\title{
Phenomenological Study of Bukidnon State University Graduate Student Scholars
}

\author{
Lolita A. Dulay \\ Elvira Sumbalan
}

\begin{abstract}
This study explored the lived experiences of the Bukidnon State University Graduate student scholars in the Mindanao Regions during the School Year 2014-2020. The study delved into the scholars' experiences in the six related factors, namely: students, BukSU faculty, BukSU administration, DepEd administration, work, and family.
\end{abstract}

A phenomenological qualitative research design was employed. Twelve graduate student scholars were the participants of the study. The triangulation approach employing interviews, focus group discussions, and document review in the gathering of data assured the validity of the findings. Participants' narratives on their lived experiences underwent transcriptions and analysis using Colaizzi's method (1978).

There were six (6) themes that surfaced-out from the lived experiences of the graduate student scholars, namely: Challenging yet, fulfilling Student-Learning Experiences; Satisfying Learning Experience with Wellrounded graduate faculty; Heart-warming learning experience with the BukSU Administration; Impressive support from the DepEd Administration; Pressured learning experience; and encouraging support system. A model showcasing the meaningful experiences of the graduate scholars and the attributes of how these scholars succeed in the pursuit of a graduate degree came out from these emerging themes.

Keywords:- $\quad$ Globalization, Internationalization, Phenomenological, Graduate Student, Scholars.

\section{INTRODUCTION}

The remarkable globally competent scheme of Bukidnon State University (BukSU) in partnership with the Department of Education (DepEd) in granting scholarship program extended to classroom teachers and school administrators paved the way among DepEd educators' career advancement and equal opportunity to succeed and improve quality of life. The Scholarship grant of BukSU creates more quality educators practicing their profession with excellent vision, mission, and goals to deliver quality education in internationalization since the university has the excellent standards and capability to produce high-caliber educators through their outstanding Doctors of Education professors. It helps strengthens educator's foundations in educational administration suited, enhanced, more equipped, innovative, humble, and ready to accept responsibilities and higher positions in their stations embodying the ideals and aspirations of the university.

The scholarship transformed graduate students holistically and become globally competent educators, an open opportunity for the scholars' professional growth and development. Earning a Master's Degree in the institution added dimension in their lives and pushed them to embrace humility. The impact of the BukSU research standard and the quality education has already transferred and imparted by the scholars to their beneficiaries in the field in DepEd, being more passionate in teaching the learners. As a result globally competent school administrators have the expertise in handling schools and become rooted with virtue and dedication. Their graduate degree leads to an open door for an immediate job promotion after graduation thus receiving bigger salaries that elevate their lives and providing a better and brighter future for their respective families, as well.

\section{THE FRAMEWORK OF THE STUDY}

These study anchors on different theories and concepts about individuals' success and failures in accomplishing tasks. The first theory is from Carl Rogers (1980), who states that for a person to achieve selffulfillment, he or she must be in a state of congruence and have direction. Self-fulfillment is an indicator of a persons' "ideal self" of who they would like to be. Thus, graduate students pursue their studies because they could be promoted as school principals and administrators, master teachers, supervisors, and directors in the future. They all aim for personal growth and self-actualization and direction.

Furthermore, the study explores the success stories of the scholars who are promoted to a higher position as a result of their hard work, perseverance, and determination in finishing their graduate degree. The demand for quality education at Bukidnon State University in terms of significant output such research is challenging yet, rewarding in the sense that the knowledge, skills, and expertise they gained can be their asset to face the challenges of the demand in education.

Jarvis (2006) noted that an individual perceives a situation in a particular manner based on what he or she has learned in previous experiences. Thus, the DepEd scholars in BukSU demonstrate their learning in their particular work in the DepEd based on what they have learned from their professors in BukSU. There is a need to look deeper and examine what learning transpired in the graduate program to understand the transition from student to 
aspiring professor. Jarvis' theory spans from birth to death. He explained that mid-life learning is a time of identity change that reflects both the changes in our lives and the processes of becoming competent educators in the field of education.

On faculty-related factors, teacher self-efficacy is influential in teacher professional commitment (Klassen et al., 2013). Self- efficacy can influence classroom performance, especially on learners with additional needs. Self-efficacy is crucial, not only for the well-being of the individual but also about their behaviors and student outcomes. There is a need that we gain a greater understanding of how self-efficacy develops.

Thus, on the BukSU administration, the full support of the faculty and the administration is exceedingly desired to succeed. Moreover, pursuing graduate studies is challenging yet fulfilling. The students should have the right attitude towards learning and academic work. Likewise, the faculty should be available and approachable for the students to help them attain their quest for excellence. Hence, for a student to be competent they should have a sense of self-efficacy to accomplish a difficult task as expected from them.

On the work-related factor of the graduate students, they are obedient to the authorities of the DepEd and BukSU. The scholars' contract of the agreement requires them to complete their degree within the time frame. In doing this, the scholars have to conform to the policies in their thesis writing heeding the advice of the thesis adviser and the thesis committee. The scholars should maintain a harmonious relationship toward the BukSU administration who gave the scholarship grant, to the BukSU professors/faculty, advisors and mentors, and all, enabling them to be happy while undertaking their graduate work.

\section{A. Statement of Objectives}

This study explored the lived experiences of BukSUDepEd graduate student scholars of the graduate program of the College of Education who graduated from the previous school year 2014-2015, up to 2019-2020.

Specifically, the study answered the question:

$>$ What are the lived experiences of BukSU-DepEd graduate student scholars in finishing their masters' degree in the following:

- Student-related;

- Faculty-related;

- BukSU administration-related;

- DepEd administration-related;

- Work-related; and

- Family-related?

What conceptual model could be designed to illustrate the meaningful experiences of the BukSU-DepEd scholars to be successful in their master's degree?

\section{RESEARCH METHODS AND DESIGN}

This study utilized a qualitative research design. Qualitative research methods inform the researcher's understanding of a phenomenon. The main objective of this study was to gain a deep and thorough understanding of the lived experiences of BukSU-DepEd scholars in the entire region of Mindanao.

Bukidnon State University (BukSU) is the locale of the study. BukSU is in the heart of Malaybalay City and is known for its mission to develop globally competitive professionals and committed to providing excellent instruction. It is one of the leading educational institutions in Mindanao offering graduate programs. Most of the graduates of the programs are currently holding significant positions, particularly in the Department of Education (DepEd) and to some private institutions in Region $\mathrm{X}$ and nearby region and even internationally.

The participants of the study were the twelve (12) BukSU-Dep Ed scholars: six graduated in the school years 2014-2015, 2015-2016, 2016-2017; 2017-2018; and 20182019. While the other six have their ongoing thesis writing during this school year, 2019-2020. They were also considered participants in this study. These graduate students came from all over Mindanao representing Regions IX, X, XII, XIII, and BARMM. The participants were purposively chosen based on the specific criteria met by the participants at the moment of selection. The data were gathered using the interview of the participants commenced after the approval of the letter by the dean, and the dissertation committee. The researcher followed the ethical processes before the actual gathering of the data took place. The interview happened in a conducive place at their most convenient time where the participants can literally give their responses to the questions on their lived experiences in the pursuit of their professional development at Bukidnon State University as DepEd scholars.

During the individual interview and the focus group discussion, the participants have ample time to answer the questions, in the language or dialect familiar to them to ensure confidence and truthfulness when conveying their experiences. The use of audio visual and video recording of the proceedings provided the researcher the ease in transcribing the discourses in the interview and focus group discussion. The transcriptions and coding of the data help the transcriber.

\section{> Transcription of Data}

An English major college teacher transcribed the results of the interview and FGD. She provided the verbatim written account of spoken words from the recorded responses. A play and replay of the recordings help to decipher the wordings in the interview. The researcher discarded irrelevant information or responses in the transcript. There was a systematic review of the transcripts grouping and coding these into themes, then analyzing the content. 


\section{$>$ Data Analysis}

The researcher analyzed the gathered data using Collaizzi (1978) method of data analysis. The analysis consisted of six steps. There were the reading and rereading of the transcribed interviews to get the thought and sense of the whole content shared by the participants. The researcher extracted relevant statements from the transcripts that directly answered the research questions. Then, there was the formulation of meaning on every essential statement of the participants after rereading thoroughly the transcript to ensure the derivation of key statements and accurate meaning.

\section{$>$ Presentation, Analysis, and Interpretation of Data}

The discussion on discovering the essence of the lived experiences of the Bukidnon State University graduate student scholar in this section proceeds through the use of matrices containing the significant statements, formulated meanings, meaning units and themes and through the use of frames of extracted statements from the transcripts of the interview to substantiate the claims. This procedure provided the means for determining the essence of the lived experiences of the BukSU graduate student scholars.

The findings revealed at least six outstanding themes and twenty-eight sub-themes that emerged from the responses of the participants. The major themes include (1) Challenging yet, fulfilling Student-Learning Experiences; (2) Satisfying Learning Experience with Well-rounded graduate faculty; (3) Heart-warming Learning Experience with the BukSU Administration; (4) Impressive Support from the DepEd Administration; (5) Pressured Learning Experience; and (6) Encouraging Support System. The succeeding sub-sections present the discussion of subthemes in each relevant theme.

\section{$>$ The Student-Related Lived Experiences of Bukidnon State University Graduate Student Scholars}

The experiences of Bukidnon State University graduate student scholars in terms of student-related factors. One of the shared experiences of the graduate scholars emerging from the data in terms of student-related factors is their challenging yet fulfilling experience as students in BukSU. This experience pointed to five subthemes that validate the major theme. These sub-themes include struggles to comply and beat deadlines, coping with academic requirements, financial pressures, working in teams, and fulfilling experiences.

\section{Sub-theme 1: Struggles to comply and beat the deadlines}

It shows that in terms of dealing with academic requirements, the graduate student scholars struggled in complying requisites to meet deadlines.In particular, one participant shared during the interview that:

"It is an arduous academic experience. Given the fact, that there was a bulk of requirements to be submitted in all the subjects on time. Such as paper works and researches considering the short time frame it was challenging yet, amazing and fulfilling educational experience as the graduate student scholars".
"It was tough, especially during the summer class meetings was every day and all three subjects-Methods of Research, (Ed203), the ecology of education (EA 201), and issues and trends (EA 2014) require paper output every day. However challenging yet, fulfilling!"

The participant's experience includes summer classes, where class schedules are recited every day with three subjects. When the three subject teachers gave requirements all at the same time, the scholars would have difficulties in complying these.

They declared in the following statements:

"I have a lot of sleepless nights and tears in compliance with my academic requirements. The biggest struggles were and still are when almost all the subjects will give a task to be submitted almost at the same time".

"Struggling and sleepless nights complying with the academic requirements".

"Being a scholar is challenging considering I am from the farthest places in Mindanao". Wherein I need to adapt to the environment, conform with the schedule and in compliance with the rigors of the requirements which makes my life challenging."

The scholar's experience suggests that one of the struggles a scholar could experience include adjusting to a new environment coupled with the fulfillment of the subjects' requirements. Many of the graduate scholars in BukSU have been to school in their undergraduate degrees for a long time. Consequently, when they enroll in the graduate program, some of them would feel strange being in a classroom again. They need to take time to get attuned to the new environment, much more in complying with the requirements.

"I struggled with the difficult subjects of the requirements, reaction papers, especially that I do not have a laptop, printer. I find it difficult also with the dialect since I am Ilonggo and my classmates are speaking Visayan dialect”.

The cited experiences of the DepEd teachers gave them a sense of pride in having been allowed to pursue graduate degrees through the scholarship that they have availed. The experience at the same time pushes scholars to a different level of perseverance. Scholarship program paved more ways for scholars in terms of professional growth and development. In fact, after earning a degree in BukSU, many of the scholars have been invited to serve as speakers in training and seminars related to research. The academic training in the university proved to help develop professionals. Additionally, the services and expertise of the graduate scholars from BukSU are often sought by their superiors when they go back to their stations after the scholarship. The journey of the graduate students in itself is a challenging yet rewarding experience. 


\section{$>$ The Faculty-Related Lived Experiences}

The experiences of Bukidnon State University graduate student scholars in terms of faculty- related factors. From the scholars' responses during the interview and Focus Group Discussion (FGD), there emerged a faculty-related theme that points to their experience in working with the satisfying learning experience with Wellrounded graduate faculty of the BukSU. Four sub-themes emerged from this major theme; these are: qualified and good-natured graduate faculty; motivating and inspiring faculty's professional background; skilled mentors; and supportive and expert advisers.

Participants' experience with the faculty from the graduate program of BukSU introduced them to the wellrounded personality of the faculty. They considered the faculty as experts and competent who possess a goodnatured personality, which includes their being approachable, accommodating, kind, and tolerant. They are also motivating and inspirational that gave the scholars the courage to face the challenges that they encounter during their stay in BukSU.

Sub-theme 1: Qualified and good-natured graduate faculty

The first sub-theme refers to the scholars' experience with the qualified and good-natured faculty members of the graduate program. The scholars believed that their professors in the graduate program are competent enough to deliver the instruction that they needed for every course or subject that they take. Participant F remarks that,

"The professors in the ELT program are all equally competent in their field of specialization. They have set the standards, pushed us to reach our potentials. Challenged us inspired us and guided us for us to meet and complete the academic requirements to earn the degree and be worthy of it".

The statement indicates that the scholars were able to experience being taught by capable teachers in terms of their field of specialization. According to the scholar, these teachers have set the standards of their program that pushed them to reach their potentials. Here, the teachers have established the measures of a true graduate program.

"Most of the instructors in Ed. Ad. during my stay at Bukidnon State University were competent. They provided substantial ideas and guided the students to where the fountain of knowledge is".

"One of the instructors who handled our subject in curriculum development was a very good professor not only extended significant insights in curriculum development but on thesis writing as well. His eloquence in research preparation which he had shared with the students resulted in the successful completion of our thesis".

The statement implies that the professor in one of the subjects in the graduate program was able to impart substantial input to the students. The scholar observed the professor's competence in terms of thesis writing. An implication to this is that the faculty of the graduate programs are capable of teaching research which is essential in a graduate program.

"They had done their best in sharing knowledge with us. Resourceful, considerate, patient, approachable, and innovative are likely the right words that described my instructors concerning their teaching performance. Our professors had always kept an eye on us regarding our responses to every topic, and they were patient in guiding and helping us with difficulties through spending extra time talking to us".

The scholar's experience with this teacher is a pleasant one. The teacher must have been so kind that the student was able to describe the experience as such. The statement clearly shows that the graduate faculty has always monitored the progress of the student. Moreover, the teacher also extends extra miles for the students by spending their time in helping them cope with the requirements of the course.

Sub-theme 2: Motivating and inspiring faculty's professional background

Another sub-theme that surfaced from the statements of the participants refers to how the graduate faculty's educational qualifications influenced their performance in the graduate program. Most of their comments direct to motivating and inspiring faculty's professional background. They are one in agreement that the professional qualifications of their teachers have inspired and motivated them to pursue and earn their graduate degrees.

Moreover, participant E says that,

"Their impressive academic portfolio alone made me thrilled and determined more finish the program no matter what it takes. Their exposures and how adept they were in research gave me the enthusiasm to emulate somehow what they have achieved. For me, being firm and consistent were teacher-factors that pushed me to the limits of my capacity whether academically and or professionally".

According to the participant, the academic accomplishments of his professors made him want to achieve his goal of completing and earning the degree. He said that the professor is worth emulating in terms of academic achievements. The scholar is impressed of their teacher being adept in research. He became enthusiastic and eager to complete the course.

"The faculty's professional background has a great impact on our performances because this provides me the feeling of trust for the institution in providing quality higher education for me being their learner. Feeling ensured with acquiring quality knowledge, I am very much honored to be part of the program which makes me boost my determination to finish the degree. Another facultyrelated factor contributes to finishing my degree is the heartwarming welcome of the faculty for us considering the far distance of our hometown to Malaybalay". 
The statement implies how the student looks up to the standards of the qualification of the professors in the graduate program. According to him, this gives him the assurance and became confident that he received a quality education because of the academic portfolio of the teacher.

“The faculty's professional background influenced me to give my best in my studies. It motivated me to be better in the program I am in. I don't want to miss a class or I'll miss something important. Other - faculty related factors that contribute to my study here in BukSU to complete my degree are their kindness. They set a standard but their smiles; words and actions tell that we could come to them and they're ready to help us".

Also, the influences of the faculty to students contribute a lot to finishing the degree. The participant stated how he tried and gave his best to do better in the program enrolled. The faculty's kindness was also pointed out by the participant through the facial countenance, words, and actions manifesting that they are willing to help the students despite the standard of the course. All these are narrated by the scholar's experience with the BukSU faculty. The testimonial of the participant demonstrates the impact of the influence of the graduate program professors on student's motivation, encouragement with inspiration, and focus on their studies.

\section{Sub-theme 3: Skilled Mentors}

The BukSU graduate student scholars were already handling positions in the department of education. For that reason, teaching the graduate program requires expertise, competence, equipped with knowledgeable and high caliber professors that graduate scholars could emulate. One scholar utters:

"We were guided by our thesis subject professors in the process of thesis writing. They provided good explanations about thesis parts and processes. Additionally, deadlines and timeline of work were set. Another thing, my adviser assisted me in working with my paper. And, guided me to create my title and in doing the different parts of my research. My professors showed expertise in the field of research".

Graduate professors at BukSU guided the students in the formulation of the thesis paper in a step-by-step manner. They discussed the process chapter-by-chapter of the research manuscript. They tried as much as possible to guide and direct the students on what to do, explaining to them the procedures and giving examples on how to write a research paper.

One of the scholar's declares that:

"One of the most admirable characteristics of my professors in BukSU was their approachability. Most of the time when we experienced difficulties or have queries on course requirements; they were just always around the corner. We can even convey our messages during times where we cross our roads on the school campus. These events provided convenience for the students and facilitated effective guidance by the professors".

One participant states:

"I was amazed by their dedication and commitment to mentoring aspiring individuals who wanted to finish a master's degree. Anyway, it was their unique style of dealing with us that opened for smooth communication between a professor and a student; then became a tool that made mentoring to be done easily. We were treated with utmost care and respect with an assurance that learning would come along; then in return, I did my best to become teachable and be mentored without any distraction".

"I was mentored to be intellectually independent at the same tine ethically and intellectually humble".

"Other professors I say that they are supportive to other scholars also".

The professors at BukSU were competently doing their duties and responsibilities in mentoring and guiding students' learning process and thereby, showing commitment and dedication in providing quality education. They dealt the students with professionalism giving utmost care and assurance of the knowledge gained.

\section{Sub-theme 4: Expert Adviser}

World-class institution provides standard quality education for every student to pursue higher education. Therefore skilled, well-versed, globally competent, and highly equipped faculty would be considered in the delivery of instruction in developing educators professionally. Participant G states:

"She had truly done her best in guiding, and mentoring me and patiently checking my manuscript".

A professor takes extra time and commitment in guiding students, in mentoring and patiently checking the manuscript. For the scholar, it was worth the effort. Professors prepare their students by allowing them to explore and craft their own researches that could enhance student's career and professional life. Participant $\mathrm{C}$ narrates the following:

"in terms of my adviser he is very brilliant and he always push us to go on with our thesis he always motivate and monitor us always. We are guided".

The BukSU Administration-Related Lived Experiences of Bukidnon State University Graduate Student Scholars

The experiences of Bukidnon State University graduate student scholars in the BukSU administration related aspect.

The graduate student scholars' experiences with the BukSU administration generate theme as a heart-warming learning experience with the BukSU Administration. From the significant statements of the participants and there were 
four (4) unit meanings, namely: considerable monetary benefits and moral support from the BukSU Administration, ease of gathering data through BukSU facilitation, sufficient but inadequate student services, and Assured promotion due to research standard set by BukSU Administration.

The BukSU graduate student scholars' experiences with the administration generated emergent themes such as heart-warming learning experience with the BukSU Administration. The heart-warming learning experiences are from the significant statements of the participants and the meaning units. The scholars received monetary incentives given by the administration, aside from the free tuition fee.

The appropriate facilities provided for learning such as library and laboratory. There is an affordable dormitory where scholars can stay. Students were aided in the conduct of studies through proper channeling of communication. There is a constant monitoring of the scholars' progress in studying at BukSU. Besides, the standards set by the graduate program in terms of research assured the scholars of their promotion after earning the degree. The research standards in the university opened doors for DepEd scholar's research findings. It also gave scholars various opportunities like mentoring other teachers in conducting research.

Sub-theme 1. Considerable Monetary Benefits and Moral Support from the BukSU Administration

The scholars' experiences in BukSU on the university administration include monetary benefits and moral support in various forms. Scholars receive financial assistance for their tuition fees, book allowance, traveling allowance, and monthly allowance. These benefits helped the scholars in some way or another during their stay in the university. One participant said that their monthly allowance from the university helped them financially when they ran out of money. The statement of the participants during the interview confirms this:

"The support given by BukSU administration is mostly on official communication to our research field or station. We also have our monthly stipend which assists us in times when we are financially depleted. I think BukSU should extend its benefits to the scholars by sponsoring the monetary honorarium to be given to the panel of experts during the different stages of the thesis writing presentations. These are a heavy financial burden to scholars.

"Aside from, though we have the book allowance but still, not enough. But again, we are so much privileged".

Most of the participants seem to agree that the monetary benefits given to the scholars by the university are not enough to sustain their stay at BukSU, still they are grateful for this opportunity. Additionally, participant $\mathrm{C}$ and $\mathrm{K}$ expressed the same experience by saying,
"The financial benefit given by the university, although not as substantial as the others, has really helped me with my studies. My monthly house rental was 2,500. With the allowance, I just need to worry the remaining 1,000 to complete my obligation".

"The book allowance, traveling allowance, kulang ra kaayo, very limited not enough knowing that I have many requirements to be submitted that time".

Aside from the monetary benefits given by the university, the scholars also received their salaries even if they are out for study leave. This benefit is good for one summer and a one-year study term in BukSU.

\section{Sub-theme 2: Ease of gathering data through BukSU facilitation \\ Another type of support received by the scholars from} the BukSU administration is in making their gathering of data a lot easy by facilitating this activity. Usually, the BukSU administration writes a letter to the agencies or institutions where the researcher could gather the needed data. In most instances, the agencies or institutions positively respond to these requests making the job of the researcher a lot easier. Correspondingly, participant $\mathrm{C}$ narrates the following:

"I felt how strong the linkage between DepEd and BukSU was during the conduct of my study in our division.

Experiences of Bukidnon State University Graduate Student Scholars with the DepEd Administration

Moreover, the limited financial conditions to pay the thesis committee and adviser during the different stages of the thesis defense also pose a challenge. What challenges the scholars during the writing phase of the thesis is in reviewing the literature. The data gathering phase comes next especially on the availability of participants. Furthermore, students find difficulty in the data analysis and how to interpret and put together in writing the narrative discussions making these comprehensible to the reader. Distance is also one of the many stumbling blocks they need to hurdle during the gathering of data. Yet, the scholarship made the implementation of the research study easy.

"To the extent that DepEd approved their involvement in my study. They have accepted my request to conduct research on some selected school heads. Following their rules and regulations in conducting researches on the field, they have played a great part in the success of my study."

\section{"Ease of access and conduct of the study."}

Based from the experiences of the participants it was not easy to conduct a study within a short time frame. For the DepEd scholars working on limited time duration it was difficult, tough and challenging. The well-built linkage between BukSU and DepEd facilitated the conduct of research among the scholars. DepEd plays a significant role 
in the success of their scholars as they gave financial and moral support. To reciprocate the support of the DepEd, the scholar follows their rules and regulations in conducting researches on the field and strived hard to finish their degree. Participant L states:

"Facilitate in the submission of the requirements, encourage taking the exam, facilitated in the enrolment when the schedule for enhancement did not warrant us to be present and clear instruction to keep us informed of our benefits in the division.

"Yes. Since they permitted me to have my collection of data in our school and they helped me in identifying my participants. They also guided me in the gathering of the basis for the problem of my study.

"They are very supportive by allowing the school personnel to participate in the conduct of my study. The student was helped in the conduct of the study."

"Allow the teachers to be involved in the focus group discussion."

"They accommodate me immediately without hesitation, they don't delay my time”.

"Yes, the higher authority of DepEd sent a memorandum for those included respondents of my study to ensure that they will actively participate in the conduction of my study".

"Moral support and the approval of letters in the conduct of the study".

"It was only by allowing me to conduct classes for a certain period purposely to gather data.

The recommendation of the DepEd for the teachers or administrators to apply for the BukSU scholarship grant is already an enormous opportunity for the student. Qualifying as a scholar is also a pride of the chosen teacher or administrator because there are a limited number of DepEd scholars accepted by BukSU every school year for the specified programs.

Some responses of the scholar Participants G, D, and F during the FGD include:

"For allowing us one of the scholars. Recommendation as one of the scholars".

Yes, the approval of the scholarship grants and moral support in the conduct of the study.

"Yes, even after the scholarship program DepEd conducted a scholarship forum focusing on our re-entry plan and also allowed us to present our study in a research forum. Presently, DepEd is monitoring our current performance and professional development.
The BukSU scholarship grant to teachers and school administrators is of great help for their professional growth and development as educators of the young Filipino learners in the Department of Education. DepEd expects that after the scholarship program of the scholars they could present the findings of their studies in a research forum. These graduate scholars could echo what they learned at BukSU and share to their colleagues their research and experiences. DepEd will also evaluate the FDP development plan of the schools to identify the next probable batch of scholars by conducting a scholarship forum focusing on the re-entry plan in the application of the BukSU-DepEd Scholarship grant. DepEd could monitor the current performance and professional development of teachers who need upgrading.

\section{Sub-theme 2: Guaranteed Assistance}

The educational organization like DepEd plays a significant role in the graduate students' experiences (Hunter \& Devine, 2016). The support given by DepEd to their scholars typically include financial assistance in terms of salaries and benefits. Aside from the monetary aspects DepEd administration also gave motivations and encouragements for the scholars to really finish their graduate studies and to be able to conduct their research.

Some of the experiences of the Participants in this regard show the following:

"The approval to avail the scholarship and the consent to conduct my study were the only support I could recall so far".

"Aside from the support in all aspects like moral and assistance, financial support is appreciated where I am receiving the full benefit granting to teachers.

For some the DepEd scholars it was a great privilege receiving all the support in all aspects like moral support and assistance. Student $\mathrm{C}$ appreciated much the full benefit granted to the scholars while on study leave, such as the complete salary, bonuses, and all the benefits.

"The schools' division office of General Santos City supported my study by giving the necessary approval to conduct the research.

"One year of study leave with pay with all the benefits we still receive despite we are on study leave. Support is also given during the data gathering period.

Likewise, participant E cites:

"DepEd provided me priceless support, allowing me to focus on my studies leaving the school that I am administering in which I am still properly compensated with complete benefits. In this scenario, I feel sincere support from DepEd helping me to grow professionally".

Moreover, participant $\mathrm{F}$ and $\mathrm{G}$ assert:

"Aside from the regular salary, DepEd helped in the smooth conduct of research study 
"Facilitating my papers, giving encouragement, moral support, and for granting a study leave with pay".

"The DepEd made their best to guide us and motivated us to keep moving. I am always inspired each day hoping that my dreams make me better. Aside from the full salary, the graduate student scholar was guided, motivated by DepEd to do better in her studies.

"They have extended my monthly salary. They supported me morally and always push me to do better.

"Full salary and benefits. Approval of the study leaves with designated officers in charge and approval without delay in conducting the data gathering.

Yes, support system in terms of salary and other benefits while I'm in study leave. The DepEd really supports scholars while in study leave".

Another relevant point by participant F shows:

"It helped me have the focus on my goal which led me somehow to become an efficient student and scholar.

The full support from the administration motivated and helped the scholars to focus and to achieve their goal, which led to becoming an efficient student and scholar. Participant B stated:

"My math co-teachers are willing to extend their help especially if I have a requirement where it needs a presence in our school. I will no longer travel and visit but instead, they can help me by doing it by themselves. Also, our division is ready to assist me, especially for the papers and documents matters.

In compliance with the requirements in her station, the co-teachers helped the teacher-scholar. The division also assisted the scholar on the papers and documentary requirements. From these gestures of the co-teachers and the division, it was evident that there is teamwork between the scholar and the administration. Participant D testifies:

"I am focused to finish the degree because I still receive everything monetary though I did not report to my station".

The monetary benefit from the administration encouraged the scholars to persevere and stay focused to excellently pursue their studies, The implication is that the extended benefits were satisfying for students. Participant B comments:

Yes, they were very supportive. In terms of the consideration given in the conduct of my study".

Scholar C recalls by saying:

"Yes. For me, the school level of governance was very supportive before, during, and after the scholarship. Starting the application procedures until graduation, the school administration was constantly in communication with me to see if I was doing well in Malaybalay City”.
The division and school administration in their region were supportive before, during, and after graduation, which added the determination for the student to perform well in their studies at BukSU until they graduated in the program. The administration's help before, during, and after the scholarship grant provided a powerful impact on the scholars' personal and professional growth. In the same way, the scholars' expressed their experiences as elaborated below:

"It has no problem in the region of Basilan the superintendent were very supportive to scholar's approval of the papers priority for the processing of documents. The administrations were responsible taking part of their responsibilities to scholars."

"Sa Bukidnon sila nag a process even in the region sa amo douments sila na tanan nag process so far so good".

It was also helpful in the division of Bukidnon since the administration processes the documents of the scholars and sends these to the office in Region X. The DepEd Region $\mathrm{X}$ takes charge to completely assist and support the scholars.

\section{The Work-Related Lived Experiences of Bukidnon State University Graduate Student Scholars}

The experiences of Bukidnon State University graduate student scholars in terms of work-related aspects. The majority of the scholars were DepEd administrators handling positions in the departments. They also handle schools and district-wide responsibilities. Even if they are on study leave, they need to follow-up the conditions of the respective schools under their supervision. Many times the administrator-scholars have difficulty in complying with their academic requirements as a student while doing multitasking jobs in the department. Other scholars have tough times since they also worked on additional requirements in their stations. Some teachers were asked by the school head to approach teachers to agree to

\section{> The Work-Related Lived Experiences of Bukidnon State University Graduate Student Scholars}

The experiences of Bukidnon State University graduate student scholars in terms of work-related aspects. The majority of the scholars were DepEd administrators handling positions in the departments. They also handle schools and district-wide responsibilities. Even if they are on study leave, they need to follow-up the conditions of the respective schools under their supervision. Many times the administrator-scholars have difficulty in complying with their academic requirements as a student while doing multitasking jobs in the department. Other scholars have tough times since they also worked on additional requirements in their stations. Some teachers were asked by the school head to approach teachers to agree to substitute with their teaching loads while on leave. Other scholars were required to submit an accomplishment report as a teacher. These hindrances contributed to the scholars' delayed submission of their requirements in BukSU. Luckily, the university allowed them to take the exam one 
week late from the schedule but still manage to finish the degree within the time frame.

The responses of the participants generated the emergent theme, which include a pressured-learning experience. There are six sub-themes, namely: challenging experience, multitasking, disturbed and worried, encountered problems, job promotion, and professional growth.

\section{$>$ The Family-Related Lived Experiences of Bukidnon State University Graduate Student Scholars \\ The experiences of Bukidnon State University} graduate student scholars in terms of family-related aspect. The emergent themes include: encouraging support system with three sub-themes, namely: emotionally and mentally disturbed being away from the family, Faith in God, Motivated and inspired by the family despite the hard times being away from the family.

Specifically, the majority of the BukSU graduate student scholars came from the farthest island in Mindanao regions. They leave their families just to study at BukSU. This situation is not easy for scholars to be away from their loved ones, especially for married students. The theme encouraging support system reminds scholars with the words of encouragement, moral support, financial, and with all the love and concern from their loved ones help them push themselves to continue despite the adversities experienced. Further, the spiritual support like prayers for the scholars to successfully finish the degree becomes vital.

\section{$>$ The Experiences of Bukidnon State University} Graduate Student Scholars in Family-Related theme

Correspondingly, the scholars were motivated and inspired as well as encouraged by their family members to combat the loneliness of being away, just to give a brighter future and better life to their respective families. The motivation to gain professional growth development necessary for the job promotion and to have a higher salary to sustain the needs of their respective families becomes essential.

\section{FINDINGS}

Based on the analysis of the data, the findings are the following:

$>$ From the lived experiences of BukSU-DepEd graduate student scholars in finishing their masters' degree, six major themes emerged. These themes include: Challenging yet Fulfilling Student-Learning Experiences; Satisfying Learning Experience with Wellrounded Graduate Faculty; Heart-warming Learning Experience with the BukSU Administration; Impressive support from the DepEd Administration; Pressured Learning Experience; and Encouraging Support System.

- Under the student-related aspect the BukSU scholars underwent challenging yet fulfilling experience. These experiences include their struggles to comply and beat deadlines, cope with academic requirements, financial pressures, working in teams and fulfilling experience.

- Under the faculty-related aspect the BukSU scholars have satisfying learning experience with well-rounded graduate faculty of the BukSU. Their experiences revealed that they are exposed to qualified and goodnatured graduate faculty; with motivating and inspiring faculty's professional background; skilled mentors; and supportive and expert advisers.

- Under the BukSU administration-related aspect, the scholars revealed a heart-warming learning experience with the BukSU Administration. These experiences include considerable monetary benefits and moral support from the BukSU Administration, the ease of gathering data through BukSU facilitation, the sufficient although non-satisfying student services, and the assurance for promotion due to their research.

- Under the DepEd administration-related aspect, the scholars experienced a satisfying support from the DepEd. These are felt on the DepEd's facilitating to make the implementation of research easy and the provision for guaranteed assistance.

- Under work-related aspect, the scholars encountered being pressured in their learning experiences. They met challenging experiences like multitasking, getting disturbed and worried, having problems, job promotion and professional growth.

- Under family-related aspect, the scholars experienced an encouraging support system. Their families encouraged them when they are emotionally and mentally disturbed being far from the family, encouraging them to have faith in God, and motivating and inspiring them despite the hard times away from the family.

$>$ A model reflecting meaningful learning experiences of the BukSU scholars is designed. The model shows the six major themes that were experienced by the scholars.

\section{CONCLUSIONS}

The BukSu-DepEd graduate scholars encountered positive, challenging, and fulfilling experiences before, during, and after their scholarship grant. These experiences were lived-through by the scholars in relation with students, faculty, BSU administration, DepEd administration, work, and family.

\section{RECOMMENDATIONS}

The following are the recommendations of the study based from the findings:

$>$ Since the DepEd scholars experienced being pressured in their learning at BuKSU there is a need for the graduate school program heads together with their faculty to meet and study the courses offered, the course syllabi, and the requirements in every course so that they could agree to lessen the burdens of the students in terms of course requirements.

- Since there are some student scholars who did not finish within a given time frame, BukSU's graduate programs 
could trace these scholars and extend guidance and assistance.

- The BukSU graduate program faculty could strengthen their instruction, especially in research, to prepare the graduate student scholar comprehensively in doing individual research studies; exposure to research presentations and research journal writing.

- The BukSU administration need to continue the scholarship program to deserving teachers and administrators in the field as this is the best extension services that BukSU could offer.

- The DepEd administration needs to create a selection committee to monitor the performance of the DepEd scholar to ensure that they graduate. Qualification for nominee should not only be on awardee but those that have Zero Unit in M.A. priority should also be given to IP's.

- The DepEd administration could unburden the scholars especially the administrators, from their work responsibilities in their respective schools so that the scholars could fully concentrate in their graduate work.

- The DepEd scholars may prepare themselves and their families on the possible problems and challenges that they will face once the scholarship is on the process.

The model could be used to enhance the policy of the administration and the quality of the delivery of instruction to achieve a $100 \%$ graduation rate among BukSU DepEd graduate student scholars

\section{REFERENCES}

[1]. Bandura, A. (1997). Self-efficacy: The exercise of control. New York: Freeman. Rust, F. (2009). Teacher research and the problem of practice. Teachers College Record, 111(8), 1882-1893.

[2]. Creswell, J.W. (2013). Qualitative Inquiry \& Research Design: Choosing Among the Five Approaches. Thousand Oaks, CA: SAGE Publications, Inc. (pp. 77-83).

[3]. Colaizzi, P. (1978). Psychological research as a phenomenologist views it. In: Valle, R. S. \& King, M. (1978). Existential Phenomenological Alternatives for Psychology. Open University Press: New York.

[4]. Maslow, A. (1954). Motivation and personality. New York: Harper.

[5]. McKinsey \& Company (2010). Closing the talent gap: Attracting and retaining top-third graduates to careers in teaching. New York: Author; McKinsey \& Company (2007). How the world's best-performing school systems come out on top. New York: Author; Fleischman, H.L., Hopstock,

[6]. Moustakas, C. (1994). Phenomenological research methods. Thousand Oaks, CA: Sage. 